Revista Brasileira de Odontologia Legal - RBOL

\title{
Diceologia Odontológica
}

\section{ATUAÇÃo do CIRURGIÃO-DENTISTA NO SERVIÇO PÚBLICO E O DIREITO À APOSENTADORIA ESPECIAL.}

\section{Performance of the dentist in the public service and the right to special retirement.}

\author{
Clea Adas Saliba GARBIN ${ }^{1}$, Denise de Toledo RÓS ${ }^{2}$, Artênio Jose Isper \\ GARBIN ${ }^{1}$, Tania Adas SALIBA ${ }^{1}$, Suzely Adas Saliba MOIMAZ ${ }^{1}$.
}

1. Departamento de Odontologia Infantil e Social da Faculdade de Odontologia de Araçatuba, UNESP, São Paulo, Brasil.

2. Mestranda do Programa de Pós Graduação em Odontologia Preventiva e Social da Faculdade de Odontologia de Araçatuba, UNESP, São Paulo, Brasil.

Informação sobre o manuscrito

Recebido em: 06 Outubro 2017

Aceito em: 06 Fevereiro 2018

\author{
Autor para contato: \\ Clea Adas Saliba Garbin \\ Departamento de Odontologia Infantil e Social \\ Rua José Bonifácio 1193, Araçatuba, São Paulo. \\ CEP: $16015-050$ \\ E-mail: cgarbin@foa.unesp.br.
}

\begin{abstract}
RESUMO
No Brasil, devido ao crescente número de idosos, aumento da longevidade da vida e diminuição da natalidade, novas propostas foram sugeridas para mudanças no requerimento da aposentadoria. $O$ Instituto Nacional do Seguro Social (INSS) é a organização pública brasileira responsável pelos serviços previdenciários. Entretanto, alguns profissionais devido a riscos físicos, biológicos e químicos de sua ocupação, podem requerer uma aposentadoria especial, mediante alguns requisitos determinados por leis. Com isso, o objetivo desta pesquisa foi verificar processos de cirurgiões-dentistas contra o INSS, investigar as principais mudanças propostas para a reforma previdenciárias e suas interferências para estes profissionais. Foi realizada pesquisa transversal, por meio de busca no endereço eletrônico do Tribunal de Justiça do Estado de São Paulo (TJSP): https://esaj.tjsp.jus.br/cjpg/, julgados em $1^{\circ} \mathrm{grau}$, no ano de 2016. Para verificar as mudanças propostas com a reforma da previdência foi realizada consulta de leis vigentes no Brasil e material disponibilizado pela previdência social. Foram encontrados 73 processos de cirurgiões-dentistas do serviço público de saúde, destes, 64 , 38\% foram para requisição da aposentadoria especial e $28,77 \%$ foram de aposentados. Do total, $82,19 \%$ dos processos obtiveram 0 parecer procedente. Com relação à reforma da previdenciária, foi visto que a aposentadoria poderá sofrer alterações com relação a idade mínima para obter o benefício. A aposentadoria especial sofrerá algumas alterações no que diz respeito ao recolhimento mensal para a previdência social. Apesar de garantida a aposentadoria especial, alguns cirurgiões-dentistas necessitaram buscar judicialmente este direito. Sobre as mudanças propostas para a reforma previdenciária, algumas poderão levar a prejuízos para os cirurgiões-dentistas.
\end{abstract}

PALAVRAS-CHAVE

Aposentadoria; Previdência social; Odontologia; Odontologia legal. 


\section{INTRODUÇÃO}

A aposentadoria por tempo de contribuição é um direito do trabalhador, que mediante um recolhimento mensal obrigatório durante 0 período ativo, independente de sua trajetória de trabalho, garante uma renda vitalícia após a velhice, visto que esta fase da vida é caracterizada pela diminuição da capacidade para realizar atividades laborais, tanto para os homens quanto para as mulheres ${ }^{1-3}$.

Esta renda é calculada de acordo com o que seria necessário para se ter uma vida adequada e digna, de uma forma que não promova alterações significativas no poder de compra dos que a recebem, sendo um substituto do salário recebido anteriormente ${ }^{4}$.

Os procedimentos e requisitos para a obtenção da aposentadoria divergem entre cada país. Na Europa, devido ao aumento da expectativa de vida da população, muitos países tiveram que promover reformas na previdência, principalmente aumentando a idade legal para aposentar e incentivando o aumento do tempo de trabalho ${ }^{3,5}$. Nos Estados Unidos, a população de idosos imigrantes estimada para 2060 é de $22 \%$ do total de idosos do país, sendo este também um dos fatores que desencadeou as mudanças na previdência Norte Americana ${ }^{6}$. Em 2011, o governo da Dinamarca decidiu aumentar a idade legal de aposentadoria por tempo de contribuição gradualmente de 65 para 67 anos, no período $2019-2022^{5}$. Na Sérvia, a reforma previdenciária é uma prioridade para o governo e as mudanças foram iniciadas em 2001, onde as primeiras alterações feitas foram com relação a ajustes para o cálculo e pagamento do benefício, sendo congelados os valores em 2008, e com relação à idade mínima para aposentadoria ocorreu um aumento gradual até a idade de 60 anos para mulheres e 65 anos para homens em $2011^{7}$.

No Brasil, a Constituição de 1988 determinou que a aposentadoria deveria ter como piso base o salário mínimo ${ }^{4}$. Com relação à requisição do benefício, existem 3 formas: a regra 85/95 progressista, que soma a idade e o tempo de contribuição, devendo ser de 85 anos para mulheres e 95 para homens; regra com 30/35 anos de contribuição, não tendo idade mínima, sendo o tempo total de contribuição de 30 anos para mulheres e 35 para homens; e regra proporcional, tendo idade mínima de 48 para mulheres e 25 anos de contribuição e 53 anos de idade com 30 anos de contribuição para homens, podendo ter decréscimo na renda de até $30 \%{ }^{8}$.

O Instituto Nacional do Seguro Social (INSS) foi criado em 1990, e tem a função de prestar os serviços previdenciários para a sociedade brasileira, gerenciando os benefícios da aposentadoria.

No entanto, algumas profissões podem apresentar riscos ocupacionais, laborais e ambientais, que quando comprovados, garantem 0 direito de um adicional de remuneração por atividades insalubres e uma aposentadoria especial, sendo preconizado desde 1943 com o Decreto-Lei $\mathrm{n} \cong$ 5.452, que aprovou a Consolidação das Leis do Trabalho (CLT) editado pela Lei no 6.514, de 22.12.1977. O artigo Art. 192 da CTL que estabelece o adicional de remuneração para atividades é respectivamente de $40 \%, 20 \%$ e $10 \%$ do salário-mínimo, segundo se classifiquem 
nos graus máximo, médio e mínimo. A Constituição da República Federativa do Brasil de 1988, também reforçou a garantia deste direito do trabalhador ${ }^{8-10}$.

O cirurgião dentista por trabalhar em ambiente insalubre, que oferece riscos ergonômicos, químicos e biológicos a saúde faz parte da categoria de profissionais que estão sob risco ocupacional ${ }^{11}$. Sendo assim, todo profissional desta classe, contribuinte da Previdência Social ou na condição de servidor público, que tem regime previdenciário próprio, poderia requerer a sua aposentadoria especial após 25 anos de serviço, não tendo idade mínima e redução no valor da aposentadoria. $O$ cálculo da renda mensal inicial de seu benefício seria de $100 \%$ do salário ${ }^{8}$. No entanto, grande parte dos cirurgiõesdentistas não sabem os benefícios da previdência $^{12}$.

Com o período atual de crise nacional e a associação com outros fatores como o aumento de longevidade da população, foi proposta uma reforma na Previdência Social brasileira, sendo assim, o objetivo deste trabalho foi verificar a existência de processos de cirurgiões-dentistas contra 0 Instituto Nacional do Seguro Social (INSS) e analisar e discutir as principais mudanças propostas para a reforma previdenciária e suas interferências para o cirurgião-dentista.

\section{METODOLOGIA}

Foi realizada pesquisa transversal, com análise de processos e de leis sobre a aposentadoria.

A análise processual foi realizada com casos julgados em $1^{\underline{a}}$ Grau, disponibilizados através do endereço eletrônico do Tribunal de Justiça do Estado de São Paulo (TJSP):

https://esaj.tjsp.jus.br/cjpg/.

Para a busca no TJSP foram utilizados os termos simplificados "dentista" e "aposentadoria", referentes ao assunto de interesse, no período de 01 de janeiro de 2016 a 31 de dezembro de 2016, e posteriormente foram selecionados apenas os processos referentes a cirurgiõesdentistas e suas aposentadorias.

Utilizou-se como critério de inclusão na pesquisa processos que tinham os cirurgiões-dentistas ativos ou aposentados como requerentes e tratavam sobre pedidos de aposentadoria ou correções de cálculos sobre aposentadoria já concedida.

Para a análise dos dados foi realizada leitura criteriosa das decisões e motivos para a instauração dos processos, por um único pesquisador.

Com relação às normas vigentes para requisitar a aposentadoria e as mudanças propostas foi feita busca de documentos oficiais vigentes atualmente no Brasil e consultas em material público disponibilizado eletronicamente pela previdência social.

Os principais documentos encontrados foram o Decreto-lei n. 05.452 , de $1^{\circ}$ de maio de 1943 , a lei oㅜ 6.514 , de 22 de dezembro de 1977, a Constituição da República Federativa do Brasil de 1988, Lei no 8.213 , de 24 de julho de 1991 e a lei $n^{\circ} 10.887$, de 18 de junho de 2004.

Está pesquisa não apresenta aprovação do comitê de ética em pesquisa (CEP), visto que foram utilizados dados públicos, de livre acesso, seguindo a 
Resolução CNS 510/16 e a Norma Operacional $01 / 2013^{13,14}$.

\section{RESULTADOS E DISCUSSÃO}

Diante da inserção das palavraschave no campo de busca do TJSP foram recuperadas 178 decisões sendo que 73 estavam no escopo da pesquisa. Os demais processos foram excluídos por não serem requeridos por cirurgiões-dentistas.

Do total de 73 processos selecionados, todos os requerentes foram cirurgiões-dentistas do serviço público de saúde. Dentre eles, 58,90\% eram homens, $71,23 \%$ eram cirurgiões-dentistas ativos, $28,77 \%$ foram requeridos aposentados. Dos processos, $82,19 \%$ obtiveram o parecer procedente (Tabela1).

Com relação aos processos improcedentes, $61,54 \%$ deles foram de cirurgiões-dentistas aposentados que requeriam adicional de gratificação para a aposentadoria. Entre os processos procedentes, $73,33 \%$ foram para a aposentadoria especial por tempo de trabalho (Tabela 2).

Tabela 1- Distribuição percentual de processos requeridos por cirurgiões-dentistas ativos ou aposentados de acordo com a resolução do processo.

\begin{tabular}{|c|c|c|c|c|c|c|c|}
\hline \multirow{3}{*}{ Requerente } & & \multicolumn{6}{|c|}{ Julgamento dos processos } \\
\hline & & \multicolumn{2}{|c|}{ Procedente } & \multicolumn{2}{|c|}{ Improcedentes } & \multicolumn{2}{|c|}{ Total } \\
\hline & & $n$ & $\%$ & $\mathrm{n}$ & $\%$ & $\mathrm{n}$ & $\%$ \\
\hline Cirurgião dentista & Masculino & 28 & 38,35 & 4 & 5,48 & 32 & 43,83 \\
\hline ativo & Feminino & 19 & 26,03 & 1 & 1,37 & 20 & 27,40 \\
\hline \multirow{2}{*}{$\begin{array}{l}\text { Cirurgião dentista } \\
\text { aposentado }\end{array}$} & Masculino & 7 & 9,59 & 4 & 5,48 & 11 & 15,07 \\
\hline & Feminino & 6 & 8,22 & 4 & 5,48 & 10 & 13,70 \\
\hline Total & & 60 & 82,19 & 13 & 17,81 & 73 & 100,00 \\
\hline
\end{tabular}

Tabela 2- Distribuição numérica e percentual de acordo com o motivo para o requerimento judicial.

\begin{tabular}{lrrrr}
\hline & \multicolumn{2}{c}{$\begin{array}{c}\text { Processos } \\
\text { improcedentes }\end{array}$} & Processos procedentes \\
\hline Motivos do processo & $\mathrm{n}$ & $\%$ & $\mathrm{n}$ & $\%$ \\
\hline Aposentadoria especial por tempo de trabalho & 3 & 23,08 & 44 & 73,33 \\
Aposentadoria por invalidez & 2 & 15,38 & 3 & 5,00 \\
Adicional de gratificação na aposentadoria & 8 & 61,54 & 13 & 21,67 \\
Total & 13 & 100,00 & 60 & 100,00 \\
\hline $\mathrm{n}=73$ & & & &
\end{tabular}

Dentre os 47 pedidos de aposentadoria especial, 44 foram procedentes e 3 tiveram resultado adverso pelo fato de não ser comprovado o trabalho em atividade insalubre pelo período de tempo exigido para requisição da aposentadoria especial.

Para os casos improcedentes para aposentadoria por invalidez, a avaliação médica constatou que a capacidade laboral 
poderia ser reestabelecida, mediante adaptações.

Nos 8 casos improcedentes para 0 adicional de gratificação, 2 deles já haviam passado do tempo para o pedido, 1 estava recebendo o benefício requerido e nos 5 restantes não foram comprovados o direito a gratificação.

Nesta pesquisa, 5 processos foram de cirurgiões-dentistas requerendo aposentadoria por invalidez. A aposentadoria por invalidez é concedida para profissionais que por algum motivo tiveram sua capacidade de trabalho diminuída e não podem mais exercer sua profissão $^{15}$.

$\mathrm{Na}$ área das profissões da saúde, os distúrbios musculoesqueléticos são apontados como a principal causa de aposentadorias precoces, sendo considerada até 4 vezes mais prevalentes entre os cirurgiões-dentistas em comparação com médicos ${ }^{15}$.

Diversos estudos apontam que 0 cirurgião-dentista adota posições incorretas durante os atendimentos e faz longas jornadas de trabalho sem pausas para recuperação muscular, acarretando em dores osteomusculares que podem afetar significativamente seu desempenho no trabalho e sua vida particular ${ }^{11,16,17}$. Os distúrbios psicológicos também foram apontados como causas frequentes para aposentadoria precoce de cirurgiõesdentistas $^{15}$.

Neste estudo também foi visto que, apesar do cirurgião-dentista atuar no serviço público de saúde e ter o direito a aposentadoria após 25 anos de trabalho, devido ao alto grau de insalubridade, alguns ainda tiveram seus pedidos negados junto ao sistema previdenciário nacional responsável pela revisão do pedido de aposentadoria, sendo necessária ação judicial para obter este direito. Do total de processos encontrados, 47 deles foram para a requisição da aposentadoria por tempo de trabalho, sendo julgados procedentes 44 destes processos.

Para se obter 0 benefício da aposentadoria o trabalhador precisa ter os requisitos mínimos exigidos pela constituição vigente no país. No entanto, a decisão para requerer a aposentadoria deve ser feita pelo próprio trabalhador, podendo ser influenciada por diversos fatores ${ }^{18,19}$.

Para alguns trabalhadores a aposentadoria pode ser percebida como um período de desvalorização, levando a diminuição da autoestima e ao sentimento de perda e inutilidade, de diminuição financeira e do companheirismo entre os colegas de trabalho. Para outros a aposentadoria representa um momento de maior liberdade e de desengajamento profissional, trazendo novas oportunidades e realizações, a expectativa de passar mais tempo com a família, de dedicar-se ao lazer ou mesmo à realização de antigos sonhos ${ }^{18}$. No caso das mulheres, por exemplo, a família pode ser fator de grande importância, devido ao maior cuidado com filhos e netos ${ }^{19}$.

Com relação aos requisitos mínimos para obtenção da aposentadoria no Brasil, desde 2016, vem sendo discutida uma nova reforma previdenciária, devido à crise atual vivida pelo país e outros fatores. Segundo estimativas feitas, as despesas do INSS já estão em torno de $8 \%$ do PIB, tendo 
projeções para chegar a 18\% em 2060.

Outro motivo apontado para a reforma seria a baixa fecundidade e aumento da longevidade de vida dos brasileiros, podendo ter sua população ativa diminuída em alguns anos ${ }^{20}$.

As alterações propostas para a Previdência Social, não afetam os atuais beneficiários ou que já possuem os requisitos para os benefícios. Porém, afetam diretamente os profissionais que não possuem a idade ou o tempo de trabalho necessários para aposentadoria. A primeira alteração proposta seria a extinção da fórmula $85 / 95^{16}$.

Para os homens com idade menor de 50 anos e mulheres menor que 45 anos, a nova proposta passa a ter idade mínima de 65 anos, podendo ser ajustável de acordo com a evolução demográfica da população, com mínimo de 25 anos de contribuição. Segurados especiais passaram a contribuir com alíquota diferenciada e periodicidade regular. No caso de homens e mulheres com idade maior de 50 e 45 anos, respectivamente, a regra terá uma transição, será feito um acréscimo de tempo de trabalho de $50 \%$ do tempo que faltaria para a requisição da aposentadoria. Para o cálculo do valor a ser pago também foram propostas mudanças ${ }^{20}$.
A Lei $\mathrm{n}^{0}$
8.213 de
1991, complementando a Constituição Federativa de 1988, versa sobre a aposentadoria especial, sendo garantida ao segurado que tiver trabalhado sujeito a condições, que causem prejuízos à saúde ou a integridade física, durante 15, 20 ou 25 anos. O tempo de trabalho e a exposição aos agentes químicos, físicos, biológicos ou a associação deles, devem ser comprovados pelo segurado perante o INSS e períodos ocasionais ou intermitentes não são considerados. Com isso, para a obtenção da aposentadoria especial, períodos em que não houve trabalho em atividades especiais como de licença saúde e férias não são contados $^{21,22}$.

Com a nova proposta para a reforma previdenciária o cirurgião-dentista, para ter direito a aposentadoria especial, deverá contribuir com uma alíquota diferenciada e periodicidade regular ${ }^{20}$.

Diante do exposto ressalta-se a necessidade de maior interesse por parte dos cirurgiões-dentistas sobre a busca pelo conhecimento e informações sobre a aposentadoria.

\section{CONCLUSÃO}

Conclui-se que, apesar de garantida a aposentadoria especial por ter atividade insalubre comprovada, alguns cirurgiõesdentistas tiveram que procurar recursos judiciais para conseguir o benefício.

Sobre as mudanças propostas para a reforma previdenciária, algumas poderão acarretar em prejuízos para os cirurgiõesdentistas, no que diz respeito ao gasto mensal com relação à previdência social.

\section{ABSTRACT}

In Brazil, because of the increasing number of elderly people, increased longevity of life and declining birth rates, new proposals were suggested for changes in the requirement for retirement. The Brazilian National Social Security Institute (INSS) is the public organization responsible for social security services. However, some workers due to the physical, biological and chemical risks of their occupation may require a special retirement, according to some requirements determined by laws. Therefore, the objective of this research was to verify dentists' processes against the INSS, to investigate the main changes proposed for social security reform and their interference for these professionals. A cross-sectional survey was carried out by 
searching the electronic address of the Court of Justice of the State of São Paulo (TJSP): https://esaj.tjsp.jus.br/cjpg/, judged in 1st degree, in the year of 2016. To verify the changes proposals with the reform of the social security was made consultation of laws in force in Brazil and available material by social security. A total of 73 dentists of the public health service were found, of which $64,38 \%$ went to special retirement and $28.77 \%$ were retired. Of the total, $82.19 \%$ of the cases obtained the relevant opinion. With regard to the pension reform, it was seen that the retirement may change with respect to the minimum age to obtain the benefit. The special retirement will have some changes as regards the monthly payment for social security. Although special retirement was guaranteed, some dental surgeons needed to apply this right in court. On the proposed changes to the pension reform, some may lead to losses for dentists.

\section{KEYWORDS}

Retirement; Social security; Dentistry; Forensic dentistry.

\section{REFERÊNCIAS}

1. Veras RP, Ramos LR, Kalache A. Crescimento da população idosa no Brasil: transformações e conseqüências na sociedade. Rev Saúde Pública. 1987; 21(3): 225-33. http://dx.doi.org/10.1590/S003489101987000300007.

2. Torres TL, Camargo BV, Boulsfield AB, Silva AO. Representações sociais e crenças normativas sobre envelhecimento. Ciênc Saúde Coletiva. 2015; 20(12):3621-30. http://dx.doi.org/10.1590/1413812320152012.01042015.

3. López SR, Montero P, Carmenate $M$, Avendano M. Functional decline over 2 years in older Spanish adults: Evidence from the Survey of Health, Ageing and Retirement in Europe. Geriatr Gerontol Int. 2014; 14(2):403-12. http://dx.doi.org/10.1111/ggi.12115.

4. Marques RM, Euzéby A. Um regime único de aposentadoria no Brasil: pontos para reflexão. Nova Econ. 2005; 15(3):11-29. http://dx.doi.org/10.1590/S0103$\underline{63512005000300001 .}$

5. Wind A, Burr $H$, Pohrt A, Hasselhorn HM, Van der Beek AJ, Rugulies R. The association of health and voluntary early retirement pension and the modifying effect of quality of supervision: Results from a Danish register-based follow-up study. Scand J Public Health. 2017; 45(5):468-75. http://dx.doi.org/10.1177/1403494817699998

6. Blanco LR, Aguila E, Gongora A, Duru OK. Retirement Planning among Hispanics: In God's Hands? J Aging Soc Policy. 2017; 29(4):311-31.

http://dx.doi.org/10.1080/08959420.2016.127 2161.

7. Milovanovic O, Radevic S, Jovanovic $M$. Legal Framework and Retirement Policies in Serbia from 1990 to 2016 - Gendered Perspective. Front Public Health. 2016; 4:208.

http://dx.doi.org/10.3389/fpubh.2016.00208.
8. Brasil. Constituição (1988). Constituição da República Federativa do Brasil. Brasília, DF. Disponível em: http://www.planalto.gov.br/ccivil 03/constituic ao/constituicao.htm. Acesso em: 8 de setembro de 2017.

9. Brasil. Decreto n. 5.452 , de $1^{\circ}$ de maio de 1943. Aprova a Consolidação das Leis do Trabalho. Disponível em: http://www.planalto.gov.br/ccivil 03/decretolei/Del5452.htm. Acesso em: 8 de setembro de 2017.

10. Brasil. Lei n.6.514, de 22 de dezembro de 1977. Altera o Capítulo V do Titulo II da Consolidação das Leis do Trabalho, relativo a segurança e medicina do trabalho e dá outras providências. Disponível em: http://www.planalto.gov.br/ccivil 03/leis/L651 4.htm. Acesso em 8 de setembro de 2017.

11. Moimaz SAS, Costa ACO, Saliba NA, Bordin D, Rovida TAS, Garbin CAS. Condições de trabalho e qualidade de vida de cirurgiõesdentistas no sistema único de saúde. Rev Ciênc Plur. 2015; 1(2):68-78.

12. Garbin CAS, Mancuso DN, Saliba TA, Michel-Crosatto E. O cirurgião-dentista e a previdência social. JBC. 2006; 24:1-6.

13. Brasil. Conselho Nacional de Saúde. Resolução $n^{\circ} 510$ de 7 de abril de 2016. Trata das especificidades éticas das pesquisas nas ciências humanas e sociais e de outras que utilizam metodologias próprias dessas áreas. Disponível em: http://conselho.saude.gov.br/resolucoes/201 6/reso510.pdf. Acesso em 05 de fevereiro de 2018.

14. Brasil. Ministério da Saúde- Conselho Nacional de Saúde. Norma Operacional $n^{\circ} 001 / 2013$ de 2013. Dispõe sobre a organização e funcionamento do Sistema CEP/CONEP, e sobre os procedimentos para submissão, avaliação e acompanhamento da pesquisa e de desenvolvimento envolvendo seres humanos. Disponível em: http://conselho.saude.gov.br/web comissoes conep/aquivos/cns\%20\%20norma\%20opera 
cional\%20001\%20-

\%20conep\%20finalizada\%2030-09.pdf.

Acesso em 05 de fevereiro de 2018.

15. Brown J, Burke FJ, Macdonald EB, Gilmour $\mathrm{H}$, Hill KB, Morris AJ, et al. Dental practitioners and ill health retirement: causes, outcomes and re-employment. $\mathrm{Br}$ Dent J. 2010; 209(5):E7. http://dx.doi.org/10.1038/sj.bdj.2010.813.

16. Garbin AJÍ, Soares GB, Arcieri RM, Garbin CAS, Siqueira CE. Musculoskeletal disorders and perception of working conditions: A survey of Brazilian dentists in São Paulo. Int $J$ Occup Med Environ Health. 2017;30(3):367-77.

http://dx.doi.org/10.13075/ijomeh.1896.0072 4 .

17. Garbin AJI, Garbin CAS, Arcieri RM, Rovida TAS, Freire ACGF. Musculoskeletal pain and ergonomic aspects of dentistry. Rev Dor. 2015; 16(2): 90-5. http://dx.doi.org/10.5935/18060013.20150018.

18. França LHFP, Menezes GS, Bendassolli PF, Macedo LSS. Aposentar-se ou continuar trabalhando? O que influencia essa decisão? Psicol Ciênc e Prof. 2013; 33(3):548-63. http://dx.doi.org/10.1590/S1414$\underline{98932013000300004}$

19. Lumsdaine RL, Vermeer SJC. Retirement Timing of Women and the Role of Care Responsibilities for Grandchildren. Demography. 2015; 52(2):433-54. http://dx.doi.org/10.1007/s13524-015-0382-5.

20. Brasil. Governo Federal: Reforma da Previdência. Previdência Social. 2017. Disponível em: http://www.previdencia.gov.br/reforma/. Acesso em: 10 de setembro de 2017

21. Brasil. Lei n.10.887, de 18 de junho de 2004. Dispõe sobre a aplicação de disposições da Emenda Constitucional $n^{\circ} 41$, de 19 de dezembro de 2003, altera dispositivos das Leis n 9.717, de 27 de novembro de 1998, 8.213 , de 24 de julho de 1991. Disponível em:

http://www.planalto.gov.br/ccivil 03/ ato2004 -2006/2004/lei//10.887.htm. Acesso em: 10 de setembro de 2017 .

22. Brasil. Lei n.8.213, de 24 de julho de 1991. Dispõe sobre os Planos de Benefícios da Previdência Social e dá outras providências. Disponível em: http://www.planalto.gov.br/ccivil 03/leis/L821 3cons.htm. Acesso em: 30 de setembro de 2017. 